\title{
La compañía volante de campaña del Valle de San Bartolomé, 1688-1752
}

\author{
Chantal Cramaussel*
}

Resumen: la compañía volante de campaña se estacionó, de 1688 a 1752, en San Bartolomé, en la provincia de Santa Bárbara, en la Nueva Vizcaya. El sustento de la tropa dependía de la población local y de los adelantos que le daba en géneros el capitán, quien a su vez dependía del mercader que lo aviaba, y muchas veces del gobernador, el cual controlaba el comercio. Al igual que los presidios, la compañía se encargaba de la defensa de los caminos y tenía que combatir a los indios rebeldes, y para ambas tareas siempre contaba con el apoyo de los indios auxiliares. El traslado de la compañía volante a San Bartolomé contribuyó a estimular el poblamiento local. Los soldados pertenecían a las capas más humildes de la sociedad, pero el cargo de capitán representó una vía de ascenso social notable. Los capitanes eran jefes militares y la paz dependía de sus lazos con los indios aún no sometidos.

Palabras clave: compañía volante; San Bartolomé; Nueva Vizcaya; presidios; indios; soldados.

* Profesora-investigadora en el Centro de Estudios Históricos de El Colegio de Michoacán (COlmich). Martínez de Navarrete 505, colonia Las Fuentes, C. P. 59699. Zamora, Michoacán, México.Teléfono: (351) 5157100. Correo electrónico: chantal@colmich.edu.mx Este trabajo es parte de los resultados del proyecto no. 250624 de Ciencia Básica 2015 de CONACYT titulado "El gran Norte novohispano-mexicano en el tiempo y el espacio: estudios sobre poblaciones y territorios en perspectiva comparada. 
Abstract: from 1688 to 1752, the CompañíaVolante de Campaña (roughly, "Flying Company") was stationed in San Bartolomé, which at that time belonged to the province of Santa Bárbara in Nueva Vizcaya. For their sustenance, those troops were dependent on the local population, on goods delivered in advance by the Captain of the Compañía, who, in turn, relied on the trader who supplied merchandise to the military and, often, also on the governor himself who controlled trade. The Compañía was entrusted with the tasks of protecting roadways and combatting rebellious Indians; activities they could not conduct effectively without the help of Indian auxiliaries. The transfer of the Compañía to San Bartolomé contributed to consolidating local settlement. While the soldiers belonged to the poorer social classes, achieving the rank of Captain represented an outstanding route towards social mobility. Captains were regional military chiefs, and peace depended largely on their relations with still unsubdued Indians.

Key words: flying company; San Bartolomé; Nueva Vizcaya; presidios; Indians; soldiers.

\section{Introducción}

La "compañía volante de campaña" fue un cuerpo de soldados que se estacionó durante 66 años en el poblado y misión de San Bartolomé (hoy Valle de Allende, Chihuahua). No era la primera de su género en la Nueva Vizcaya, y contribuyó al sistema defensivo de la provincia pero, como era difícil sostenerla, al igual que los presidios, generó muchos problemas.

Por otra parte, la instalación de un cuartel en 1688 en el Valle de San Bartolomé estimuló el poblamiento local. Los soldados, en su gran mayoría originarios de otros pueblos de la Nueva Vizcaya, contrajeron matrimonio en San Bartolomé y tuvieron descendencia. Aunque estas alianzas no los hicieron ricos, pertenecer a la compañía significaba ingresar a un grupo social particular que había hecho de 
la vida militar un modus vivendi. Su suerte era muy distinta a la de los capitanes, para los cuales encabezar la compañía sí representó una vía rápida de ascenso social.

La investigación se basa principalmente en documentos inéditos conservados en el Archivo Histórico Municipal de Hidalgo de Parral, Chihuahua (AHMP). ${ }^{1}$

\section{Las compañías volantes y los presidios de la Nueva Vizcaya}

La primera compañía volante de la gobernación de la Nueva Vizcaya fue fundada en 1655; se componía de una escuadra de 29 soldados y un capitán, una parte estaba estacionada en Parral, donde residía el gobernador de la entidad desde 1632, y otra en Durango, donde protegía al obispo de la diócesis (Porras Muñoz 2006, 321-335). Pero sus integrantes no radicaban en ningún lugar en especial, como lo indica el nombre de ese cuerpo armado, y por esta razón se decía que tenía "pie de ejército en el reino",2 es decir, que su asiento correspondía al territorio de la Nueva Vizcaya en general. La compañía tenía que proporcionar escolta a mercaderes y viajeros, y salir en contra de los indios enemigos cada vez que se necesitaba. Sin embargo, en el cuartel, donde se dejaba parte de la caballada, permanecían algunos soldados acompañados tal vez de indios auxiliares. ${ }^{3}$

La compañía volante dependía directamente del gobernador, a quien se acusaba de utilizarla en beneficio propio. Él designaba a los comandantes, así como a los capitanes de los presidios (con

1 Este artículo fue elaborado a sugerencia de Rita Soto Torres, en Valle de Allende, quien quería saber más acerca de la compañía volante. Ella proporcionó documentos, ayudó a paleografiar otras fuentes en el AHMP y le brindó hospitalidad en su casa de Valle de Allende, a la autora, quien le está muy agradecida, da las gracias también a Roberto Baca, el director del AHMP, sin su ayuda no se hubiera podido reunir en un tiempo récord todos los documentos analizados a continuación. También se le agradece a Manuel Rosales, director del Centro Cultural Casa Camargo, en Ciudad Camargo, Chihuahua, quien conoce todo acerca del presidio de Conchos; le ofreció para este artículo de manera muy generosa información que ya tenía compilada. Algunas de las ideas vertidas en el presente trabajo se encuentran en la introducción de Chantal Cramaussel y Salvador Álvarez (1997, 9-17).

2 AHMP. FC.D33.23.180. Juicio de residencia de Martín de Alday, 1721.

3 Esta protección era considerada necesaria, como lo revela la airada protesta del obispo cuando, en el siglo XVII, se trató de remover la compañía de la ciudad de Durango (Porras Muñoz 2006, 333). 
excepción del de Sinaloa, en el siglo XVII), y pugnaba siempre para que se crearan nuevos cuerpos armados. En 1665 surgió una segunda compañía volante, esta vez en Saltillo (Porras Muñoz 2006, 343).

Las funciones de las compañías volantes eran semejantes a las de los presidios, la única diferencia era que éstos se ubicaban en un verdadero fuerte, donde radicaban los soldados durante todo el año. El traslado de la compañía volante de Parral a San Bartolomé formó parte de la reorganización general de los presidios, que tuvo lugar a finales del siglo XVII. Los primeros se habían fundado al sur del río Florido, en las zonas más conflictivas que contaban con poca población bajo control colonial. En las regiones mejor pobladas, como lo era el corazón de la provincia de Santa Bárbara, a la que pertenecía San Bartolomé, los hacendados y los encomenderos protegían militarmente al vecindario por medio de sus sirvientes (Álvarez 1999, 48-71).

La situación no cambió en las últimas décadas del siglo XVII, pero la ubicación de los nuevos presidios, que se crearon de 1683 a 1688, tuvo que ver sobre todo con la protección de los caminos más transitados. Reforzaron la presencia militar de la Corona a lo largo de los dos caminos principales de la Nueva Vizcaya, el de Sonora y el de Santa Fe, donde sólo existía el presidio de San Miguel del Cerro Gordo, fundado en 1646, en un lugar despoblado y desértico situado entre Zacatecas y Parral. En la década de 1680 se extinguieron los de San Hipólito y San Sebastián, en la vertiente occidental de la Sierra Madre Occidental, al oeste de Durango, pero se mantuvo el antiguo presidio de Santa Catalina de Tepehuanes, que estaba en el camino de Topia, el cual unía el altiplano con la costa del Pacífico (Porras Muñoz 2006, 353).

La Corona autorizó que el sustento de los nuevos presidios corriera a cargo de la Real Hacienda. Se trataba de impedir que sucediera una derrota semejante a la del Nuevo México, de donde los españoles tuvieron que retirarse en 1680 (Porras Muñoz 2006, 321-368). Después de la rebelión de los indios pueblo, en 1683, se fundó el presidio de Nuestra Señora del Pilar y el de San José del Paso del Norte, cerca de la misión franciscana de Nuestra Señora de Guadalupe, donde se habían refugiado los españoles e indios amigos después de la insurrección general. En virtud de la real cédula del 22 de diciembre de 1685, en los años siguientes surgieron los de San Francisco de 
Conchos y de Nuestra Señora de la Concepción de El Pasaje (en la jurisdicción de Cuencamé), en 1686, y el de San Pedro El Gallo, en 1688, situados todos en el camino real de tierra adentro entre México, Parral y el Nuevo México. A partir de 1686, la protección de la ruta entre Parral y Sonora corrió a cargo del presidio de Casas Grandes, que se trasladó finalmente a Janos en 1690; al este del bolsón de Mapimí se establecieron los de Coahuila, en Monclova, en 1675, y de San Juan Bautista del Río Grande, en 1701, que pertenecieron a la Nueva Vizcaya hasta 1787 (Gerhard 1996, 408-409). La compañía volante de campaña de Sonora conformada, en 1691, por soldados sacados de presidios ya existentes, se estacionó en Santa Rosa de Corodéguachi o Fronteras, en el camino de Janos a la provincia de Sonora. Excepción a la regla fue la creación, en 1711, del de Mapimí, ubicado fuera del camino real y donde los soldados se encargaban de cuidar a los mineros y partir en campaña contra los indios rebeldes (Porras Muñoz 2006, 354 y 2004, 54).

La compañía volante de campaña fue establecida en el Valle de San Bartolomé por el sargento mayor Juan Isidro Pardiñas, en 1688, al principio de su mandato como gobernador de la Nueva Vizcaya. En 1691, el conde de Gálves, virrey de la Nueva España, le añadió diez hombres más, ya que tenía sólo 20 (Almada s/f, 16). ${ }^{4} \mathrm{Al}$ parecer, ese número varió con el tiempo; en 1693 eran 35 soldados (Porras Muñoz 2006, 353-360), ${ }^{5}$ y en las primeras décadas del siglo XVIII la tropa se componía de 30 hombres, como se verá más adelante.

La compañía volante fue llamada indistintamente del Valle de San Bartolomé o de Parral, ya que antes parte de la tropa se encontraba en ese último real minero, situado a 25 kilómetros al este de San Bartolomé. Pero las minas de San José del Parral estaban en decadencia y las populosas haciendas situadas en la jurisdicción del Valle de San Bartolomé eran prósperas. Además, éste se ubicaba en el paso del camino real hacia otras regiones que se estaban poblando con rapidez,

4 Este autor parece ignorar que la compañía de campaña existía desde 1655, y no cita sus fuentes.

5 Había entonces un total de 381 hombres de armas pagados por la Corona en la Nueva Vizcaya, cada presidio tenía 50, con excepción del de Cerro Gordo, que tenía 23, la compañía volante contaba sólo con 35 y la escuadra de Durango con 15. Los gastos ocasionados por el sostenimiento de las tropas presidiales y demás cuerpos militares ascendían a 170000 pesos. 
mientras que Parral quedaba al margen de él. Hacia el norte destacaba el real de Santa Rosa de Cusihuiriachi, descubierto en 1686 en la ruta hacia la provincia de Sonora, donde también se estaban explotando minas y desde donde eran frecuentes los envíos de mano de obra india y ganado a la Nueva Vizcaya central.

Debido a que en la compañía volante de San Bartolomé el cuerpo militar no tenía que residir de manera permanente en el pueblo, sino en donde las necesidades de defensa fueran más apremiantes, la construcción de un fuerte resultaba superflua. ${ }^{6}$ Los soldados no radicaban alrededor de la casa del capitán, como en el presidio de Janos o de El Paso del Norte, sino que vivían en moradas dispersas por el pueblo con sus familias. Sin embargo, existió un "cuartel”, de ubicación desconocida, en el actual Valle de Allende, donde se alojó el visitador Pedro de Rivera, en 1726. Tal vez era una antigua morada habilitada para tal efecto. Al hablar de su paso por San Bartolomé, Pedro de Rivera precisó:

Valle de San Bartolomé, población de españoles, mestizos y mulatos, con parroquia y convento de religiosos de San Francisco: sus tierras producen todo género de semillas, de que hay cuantiosas labores; y es abundante de frutas y legumbres. Tiene establecido su cuartel en este paraje la compañía de campaña, donde paré (1736).

El sostenimiento de la compañía de campaña entraba en los gastos generales causados por los presidios de la gobernación, a pesar de que no se consideraba como uno verdadero. En 1726, Pedro de Rivera en su diario calificó de "presidio" al pueblo de San Bartolomé, al cual llegó el 29 de diciembre: "El día once de enero de mil setecientos y veintiséis, después de haber evacuado la visita de este presidio, hice salida de él”. Tres años antes, Gregorio Álvarez Tuñón y Quiroz ${ }^{7}$ había visitado la compañía volante junto con los demás presidios de la gobernación.

6 Sin embargo, parece que en algún momento se trató de construir una muralla para circundar la plaza de San Bartolomé, en la que se ubicaba el convento franciscano. Tanto al este como al oeste de la plaza hay casas que cuentan con muros extraordinariamente anchos, de $1.90 \mathrm{y}$ 2.10 metros.

7 AHMP. FC.601.002.025. "Autos de visita de Gregorio Álvarez Tuñón y Quiroz, visitador general de las armas en Nueva Vizcaya”, 1723. 
Una de las funciones de la compañía volante de campaña de Valle de San Bartolomé consistía en cuidar a la población del sur de la antigua provincia de Santa Bárbara, dispersa en muchas haciendas y estancias, a lo largo de los afluentes del río Conchos, donde se extendían las tierras de labor de riego. Hasta entonces la protección militar había recaído en los propios vecinos y, sobre todo, en los encomenderos y los dueños de las haciendas, que destinaban parte de sus sirvientes a la defensa de los asentamientos de la región. ${ }^{8}$ Una vez establecida la compañía volante, los soldados compelían también a los indios a que acudieran a laborar, por vía de repartimiento, a las haciendas de los españoles. ${ }^{9}$

Pero el objetivo más importante de la compañía volante era proteger el camino real de tierra adentro, principal eje comercial y de comunicación entre Santa Fe, en el Nuevo México, Durango, la capital de la gobernación donde se quintaba la plata, y la ciudad de México, sede de los poderes virreinales. Hacia el sur, la compañía aseguraba parte de la protección militar de ese camino, se encargaba de escoltar a los trajinantes hasta el arroyo de La Parida, donde tomaban el relevo los soldados de Cerro Gordo. ${ }^{10}$ En 1715 se decía que entraban anualmente 5 mil mulas cargadas de bienes para abastecer, desde el sur, a la Nueva Vizcaya, doce años después eran 7 mil. En 1721, los "cordones" o caravanas de viajeros y comerciantes eran mensuales y los "convoyaban" indios amigos y soldados; ${ }^{11}$ cada presidio así como la compañía volante aportaban diez soldados para tal efecto. ${ }^{12}$

En 1752, la compañía volante de campaña del Valle de San Bartolomé se trasladó a Nuestra Señora de Huejuquilla, situada a unos

8 Salvador Álvarez (1999) señaló la estrecha relación entre los presidios y las haciendas; la Corona subsidiaba a los hacendados, les nombraba un capitán de presidio y pagaba el salario a los soldados, que el capitán cobraba por ellos en Durango, y mientras tanto les adelantaba bienes en su propia tienda.

9 AHMP. FC.C1.1.18. "Consulta por Martín de Alday sobre las contribuciones de los vecinos para gastos de paz y guerra así como el cobro de las alcabalas para el resguardo de los caminos", 1721.

10 AHMP. FC.C11.017.177. "Diligencias hechas para las providencias que se han de tomar contra los indios enemigos", 1721.

11 En el AHMP. FC.C11.017.177 se mencionan 7 mil mulas, mientras que en AHMP. FC.C01.001.014: "Los capitanes de los presidios de la Nueva Vizcaya solicitando se envíen recursos para el avío de los presidios y el pago de los sueldos de los soldados" 1715 , se alude a 5 mil mulas.

12 AHMP. FC.C 11.017.177. "Diligencias hechas para las providencias que se han de tomar contra los indios enemigos", 1721. 
50 kilómetros hacia el este, en una zona más conflictiva en la que se estableció un verdadero presidio. En territorios donde las hostilidades eran frecuentes, al norte y al este de la ciudad de Chihuahua ${ }^{13}$ y en la provincia de Coahuila (Gerhard 1996, 408), después se fundaron los demás presidios y compañías volantes de la época colonial, pero casi todos los anteriores, al igual que la compañía volante de San Bartolomé, fueron suprimidos.

\section{El sostenimiento de la compañía volante}

Los miembros de la compañía volante cobraban sus salarios en la real caja de Durango, donde se pagaban los impuestos de la época, en particular el diezmo sobre la plata extraída. ${ }^{14}$ Pero con mucha frecuencia la real caja se quedaba sin fondos, y los soldados no podían cobrar sus salarios que, a veces, la Corona tardaba varios años en saldar. En 1688, el gobernador Juan Isidro Pardiñas informaba que los 30 soldados estaban esperando recibir su salario desde hacía un año, porque el virrey había ordenado que los oficiales de la real caja de Durango remitieran todo el efectivo a México (Porras Muñoz 2006, 267-268).

Los soldados no percibían dinero, sino que el capitán les adelantaba, a cuenta de su salario, los bienes y víveres que necesitaban de modo que "el aprovisionamiento de los soldados era, pues, un negocio para los capitanes" (Porras Muñoz 2006, 270), pues ellos fijaban los precios. Pero la cabeza de todo ese comercio era el gobernador, quien tenía un trato preferencial con algún mercader de la ciudad de México (Porras Muñoz 2001, 160), que quizá le había adelantado dinero para que pudiera comprar el cargo, o instalarse en el real de minas. Había también comerciantes que abastecían directamente a los capitanes y a los hacendados, quienes tenían deudas constantes con ellos. Cuando

13 Clementina Campos Reyes está elaborando su tesis doctoral sobre Namiquipa, donde la impronta sobre el poblamiento de la compañía volante, establecida en 1778, fue importante. Se pueden ver aspectos demográficos de Namiquipa, en el norte de la Nueva Vizcaya (18021815), en: Revista de Historia 4: 115-132 (2012).

14 No era el caso de todos los presidios de la Nueva Vizcaya, los soldados del de Conchos cobraban en Guanajuato, los de El Pasaje, en Zacatecas, y los de El Gallo, en Sombrerete: AHMP. FC.C1.1.18. “Consulta por Martín de Alday...”, 1721. 
se atrasaba la paga de los salarios, las deudas de los capitanes con sus aviadores crecían, y éstos les cobraban réditos cada vez más altos, llamados "premios", los cuales recaían, desde luego, en los soldados que veían subir por las nubes los precios de las mercancías que les adelantaba el capitán.

Los soldados no recibían gratuitamente ni las armas, la pólvora, los caballos, la armadura de los equinos, llamada coleto o cuera (un peto de cuero), ni la adarga, que eran los objetos indispensables para el oficio castrense, sino que el capitán se los adelantaba, y se los descontaba después de su salario (Porras Muñoz 2006, 270). Cuando estaban en el Valle de San Bartolomé, los soldados de la compañía volante, al igual que los presidiales, labraban sus propios campos, es probable que gracias a la ayuda de sus familiares, puesto que no estaban siempre presentes en el momento de las siembras y las cosechas. Pero también recibían raciones, al igual que los sirvientes de las haciendas, que consistían en harina, maíz, carne, manteca, piloncillo, sal, jabón y cigarros. ${ }^{15}$ Hasta 1726, en razón de sus prolongadas ausencias, el salario de los integrantes de la compañía volante era de 450 pesos, excedía por 100 al de los soldados presidiales.

Además de los salarios, el mantenimiento de la compañía implicaba muchos otros gastos; se tenía que asegurar la alimentación de centenares de caballos y mulas, y aprovisionar a los propios soldados cuando salían en campaña, a veces durante varios meses. El fondo de paz y guerra, que constaba primero de 4 mil y después de 6 mil pesos y estaba impuesto también sobre la real caja de Durango, no bastaba para costear todas las campañas. Al preparar una nueva expedición militar se recurría siempre a la generosidad de los vecinos, que además de hombres armados aportaban dinero, animales o harina en función de sus posibilidades. Había que pagar también a los indios auxiliares que desempeñaban un papel fundamental, tanto en la protección de viajeros y mercaderes como en las guerras. ${ }^{16}$ En 1718 se resolvió: “que

15 Cuando menos estas provisiones eran las que recibían los soldados de la compañía volante de campaña en 1784: "Cobro de deudas por aprovisionamiento de tropa". 25 de abril de 1784, en el presidio de Guejuquilla: AHMP. FC.004.084.

16 Por ejemplo, en 1721 se reunieron donativos en Parral, Chihuahua y San Bartolomé para una campaña de tres meses: AHMP.FC.C1.1.18 "Consulta por Martín de Alday...” Únicamente en Sonora existieron presidios a cargo de indios auxiliares, como los ópatas de Bavispe, Bacoachi y Buenavista en los años ochenta del siglo XviII (Borrero Silva y Velarde Cadena 2013, 95-117). 
los vecinos de todos los gremios contribuyan para la manutención y paga de los indios que acompañan a los soldados así en los cordones que entran y salen como en la correrías, seguimientos, y alcances que se han de hacer a los indios enemigos". ${ }^{17}$

Los indios participaban como espías, guías y combatientes en todas las campañas; en 1691 se emprendió una punitiva contra los rebeldes que habían atacado el presidio de Santa Catalina de Tepehuanes (hoy Tepehuanes, Durango). En la expedición, que duró 85 días, participaron 111 soldados, entre los cuales estaban 23 miembros de la compañía volante, y 181 indios de arcos y flecha (conchos, cabezas, boboles de Coahuila y tepehuanes). Se alistaron 129 mulas para cargar con el bastimento de casi tres centenares de hombres. En 1693 fueron 80 soldados alistados, 20 de la compañía volante y 300 indios (Porras Muñoz 2006, 274-275). Dos años después se reunió de nuevo una tropa de auxiliares para combatir a los indios de la Alta Sonora; de nuevo, en 1697, los españoles recurrieron a 235 indios auxiliares, para ir a pelear contra los rebeldes. Griffen (1979, 4951) documentó que muchas veces se pidieron indios auxiliares en las misiones, en 1704, 1715, 1726 y 1740. Para cubrir el financiamiento de las campañas, el gobernador Martín de Alday quiso cobrar un peaje de 3 pesos sobre cada mula que transitara por el presidio El Pasaje, donde era capitán vitalicio, un peso más para las que cargaban los comestibles y uno por cada fardo de ropa. Pero los vecinos de la Nueva Vizcaya quedarían exentos de ese impuesto. ${ }^{18}$ Hay que recordar que en esa gobernación no se pagaba el impuesto de la alcabala sobre las transacciones comerciales, debido a que los habitantes de la región tenían muchos gastos para defenderse de los indios de guerra (Porras Muñoz 2006, 408).

Poco tiempo después de la fundación de los nuevos presidios en el camino real y del traslado de la compañía volante a San Bartolomé, tanto el virrey como el gobernador, Martín de Rebollar, decidieron emprender campañas ofensivas en contra de los indios insumisos

17 AHMP.FC.C05.001.013 “Lista de donativos de los vecinos del valle de San Bartolomé y el real de San José del Parral...”, 1718.

18 AHMP.FC.C1.1.18, "Consulta por Martín de Alday sobre las contribuciones de los vecinos para gastos de paz y guerra así como el cobro de las alcabalas para el resguardo de los caminos", 1721 . 
en los territorios todavía fuera del control colonial (Porras Muñoz 2006, 271), que desembocaron en un largo periodo de guerra abierta intermitente al oriente y noreste de provincia de Santa Bárbara. Fueron expediciones muy costosas y violentas que no siempre resultaron en victorias para los españoles, pero en las que las matanzas y las tomas de cautivos eran frecuentes (Cramaussel,2014).

Los capitanes y los soldados atribuían la carencia de armas, pólvora y caballos que padecían a los atrasos en el pago de los salarios. En 1722, los miembros de la compañía volante explicaban que les faltaban caballos debido a la reciente contienda con los indios rebeldes y "por las inclemencias del tiempo"; sólo les quedaban 92 equinos, en lugar de los 300 que imponía el reglamento. Los soldados también se quejaron de que se les descontaba parte de su salario para solventar la compañía de Coahuila, recién constituida, y también tenían que contribuir con los gastos que se hacían en la ciudad de México, cuando se despachaba a los soldados a la capital del virreinato. ${ }^{19}$ Tal vez esta situación provocó la deserción de 24 soldados de San Francisco de Conchos, ocurrida en agosto de $1713 .^{20}$

En 1715, el retraso en la paga de los salarios volvió a causar un problema mayor, del que se quejaba José Sarmiento, el comandante de la compañía volante, quien afirmaba que mientras que en la centuria anterior se estilaba cobrar los salarios cada trimestre, a principios del siglo XVIII ni siquiera se pagaban cada año con puntualidad. Los soldados de San Francisco de Conchos, Cerro Gordo y de la compañía volante se habían retirado a los montes en señal de protesta; obtuvieron un despacho indultorio del virrey, que los hubiera podido acusar de deserción y, en consecuencia, condenarlos a la pena capital. Los soldados volvieron a sus presidios, pero varios meses más siguieron sin paga, por lo que se negaban a prestar los servicios que se les pedía. $^{21}$

AHMP.FC.CC01.002.025. "Autos de visita de Gregorio Álvarez Tuñón y Quiroz, visitador general de las armas de la Nueva Vizcaya”, San Bartolomé, 11 de marzo de 1723.

20 AHMP.FC.C E14.031.123. El capitán Beasoain otorga poder en Parral para que se tramite en la ciudad de México lo conveniente para que se castigue a los culpables de esa "sublevación" de la que fueron cómplices sus demás soldados y cabos, 1713. Documento proporcionado por Roberto Baca.

21 AHMP.FC.C01.001.014. "Los capitanes de los presidios de la Nueva Vizcaya solicitando se envíen recursos para el avío de los presidios y el pago de los sueldos de los soldados", 1715. 
En 1724, Pedro de Rivera fue comisionado por el rey para realizar una visita general a los presidios, que duró casi tres años. Se trataba, entre otras cosas, de aligerar los gastos de la Corona que tenía que enfrentarse a erogaciones crecientes, ocasionadas por las guerras europeas. El visitador recomendó abolir algunos presidios (Mapimí, El Pasaje y El Gallo), pero no aconsejó suprimir la compañía volante del Valle de San Bartolomé, ni siquiera disminuir el número de sus miembros. Los capitanes cobraban 600 pesos al año y los soldados 450; la compañía de campaña contaba con tres oficiales: el capitán, su teniente y un sargento. Pedro de Rivera pensó que los salarios eran excesivos en todos los presidios, y sugirió a la Corona una reducción de 100 pesos para todos. Además, se sabía que los soldados les cobraban a los que escoltaban por el camino, y que también vendían a los cautivos que tomaban presos durante las campañas punitivas, por lo que tenían ingresos complementarios. El visitador quiso que el capitán dejara de aprovecharse del monopolio de abasto del presidio, negocio jugoso que consistía en firmar un contrato con algún comerciante para obtener los bienes que les adelantaba a los soldados a título de su salario por cobrar en la caja real de la ciudad de Durango. Además de proponer una reducción del salario de los soldados, también le recomendó al rey pagarles menos a los indios auxiliares. Por otra parte, consideró innecesaria la cantidad de diez caballos por soldado, opinaba que con seis era suficiente (De Rivera 1736, 53-55).

El virrey Casafuerte tomó en consideración algunas de las reformas propuestas por Pedro de Rivera en el reglamento expedido el 20 de abril de 1726, a menos de un año de la visita que se efectuó en agosto. Se impuso la reducción salarial sugerida por el visitador, que motivó el descontento general. Esta rebaja se añadía a los salarios devengados por la Corona, desde hacía dos años. Además, se trataba de conformar un nuevo presidio, el de Santa Rosa del Sacramento (hoy Múzquiz, Coahuila), erigido finalmente en 1737 (Porras Muñoz 2004, 109), por lo que también se pidió contribución a los pobres soldados.

En 1727, los soldados de Cerro Gordo, El Pasaje, Mapimí y Valle de San Bartolomé quisieron renunciar a sus plazas militares, y se negaron a entregar a sus capitanes las armas y caballos que eran suyos. Habían decidido dejar de escoltar a los transeúntes del camino real, y de perseguir a los indios enemigos, si no se les pagaba. Su representación, enviada al gobernador, fue respaldada por los capitanes quienes de hecho eran los más agraviados, ya que cobraban los salarios de la 
tropa en la caja real; estaban endeudados con los comerciantes, que les adelantaban los bienes para que a su vez se los distribuyeran a los soldados. El gobernador turnó esa representación al marqués de Casafuerte, virrey de la Nueva España. Además, los soldados acusaron al visitador Pedro de Rivera de haberlos engañado prometiéndoles escopetas y municiones, que a la fecha no habían recibido. ${ }^{22}$

Portar armas de fuego se consideraba necesario, aunque su utilidad dejaba que desear, en primer lugar porque a los soldados les faltaba pólvora. En 1717 se empadronó en dos ocasiones a los soldados de la compañía volante, el 8 de agosto, fecha en la que faltaron algunos, y el 20 de octubre, cuando supuestamente se encontraban todos en el Valle de San Bartolomé. ${ }^{23}$ Las armas que se mencionan en las listas son las siguientes: escopeta, espada, lanza, cuera, adarga, pólvora, balas, pistola y flechas en dos casos; sólo el alférez no tenía escopeta. No había huella de mosquete, un arma de fuego más larga que la escopeta, y ningún soldado tenía más de una pistola. Tampoco se encontró alusión al arcabuz, otra arma de fuego de menor calibre y alcance, que cayó en desuso a finales del siglo XVII, cuando se propuso entregar mosquetes a los soldados y dos quintales de pólvora a cada presidio. De todas maneras, como lo comenta Guillermo Porras Muñoz:

ninguna de las armas de fuego era eficaz en las guerras contra los indios por la lentitud con se volvía a preparar para disparar de nuevo, tiempo en el cual un indio podía disparar veinte o más flechas hacia su contrincante. Los soldados, pues, no disparaban su arcabuz o su mosquete ya que al hacerlo se quedaban de inmediato desarmados, más bien las utilizaban para apuntar hacia el enemigo o para cubrir desde lejos a los indios auxiliares que entraban en combate. La verdadera arma de los soldados presidiales era la espada, que tenía utilidad solamente en las lides de cuerpo a cuerpo.Y que superaba por su consistencia a las armas más endebles de los indígenas, las lanzas también eran eficaces $(2006,353)$.

AHMP.FC.C1.2.32. "Testimonios de los autos que se han formado y remetido al excelentísimo virrey de la Nueva España en orden a la retirada que han hecho los soldados de algunos presidios de este reino para el quite o rebajo de los 100 pesos", 1727.

23 AHMP.FC.C10. 002037. "Listas remetidas por los capitanes de las compañías y presidios de esta gobernación”, 1717 . 
El sargento Miguel de Talavera, que en 1717 contaba con la mayor cantidad de caballos, poseía además diez cargas de flechas, y Pedro de la Riba tenía ocho, un número considerable del que disponían probablemente todos los soldados. Tuvieron que haber tenido también arcos, aunque no se mencionara por no formar parte de las armas obligatorias. No todos tenían lanza y espada, tal vez porque cargar con esas dos armas blancas al mismo tiempo les estorbaba para sus movimientos; 12 de los 30 miembros de la compañía optaron por una u otra. El equipo completo era tan pesado que lo llevaban las mulas, que cargaban también con el abasto. Para aligerar su atuendo, a principios del siglo XVII, los sombreros sustituyeron a los yelmos (Porras Muñoz 2006, 270). En agosto de 1717, los soldados tenían media libra de pólvora, una cantidad mucho menor a la obligatoria. Todos cargaban con 50 balas, aunque unos meses antes Javier Sotelo, José Gutiérrez y Pedro Sapien habían registrado 60 y los demás 50.

En el segundo padrón de soldados de la compañía volante de 1717 se mencionan las mismas armas y seis caballos para todos, cuando en agosto las armas así como el número de equinos era variable (entre 2 y 12). De hecho, sería extraño que todos tuvieran la misma cantidad de caballos. Es probable que esta segunda lista no correspondiera a la realidad, pero que el visitador la levantó para favorecer al capitán.

Francisco R. Almada $(1968,430)$ cita un documento posterior, de 1771, que data de la visita de O'Connor a los presidios. Las armas requeridas eran más o menos las mismas que medio siglo antes, y se menciona la vestimenta, el armamento y el equipo de montar de los soldados:

Vestimenta:

1 chupa $^{24}$ corta de tripe o paño azul con un collarín encarnado, botón dorado, collarín de tripe azul; 1 calzón; 1 capa de paño azul; 1 cartuchera; 1 cuera; 1 bandolera de gamuza con el nombre del presidio bordado; ${ }^{25} 1$ corbatín negro; 1 par de zapatos; 1 par de botas.

24 Parte del vestido que cubría el tronco del cuerpo con cuatro faldillones, que colgaban de la cintura para abajo y con mangas ajustadas en el traje militar antiguo.

25 Correa que cruza por el pecho y la espalda, y por el remate lleva un gancho para colgar un arma de fuego. 


\section{Armamento:}

1 espada ancha de caballería; 1 lanza; 1 adarga; 1 mosquete; 2 pistolas; 6 libras de pólvora; 4 libras de pólvora por cuenta propia.

Equipo de montar, además de una mula para la carga: 7 caballos; 1 silla vaquera con mochila; Corazas; cojinillos; estribos de madera.

\section{La soldadesca y el ascenso social de los capitanes}

En los padrones de la compañía volante de 1717, 1720 y 1723 no aparece el origen geográfico de los soldados ni su calidad, datos que sí se señalan en los de Mapimí y El Gallo, de 1717 (véase anexos 3 y 4), ${ }^{26}$ pero el origen de los de la compañía volante tuvo que haber sido semejante. La mayoría provenía de la Nueva Vizcaya, varios habían nacido en la capital de la gobernación, y unos cuantos eran oriundos de algún presidio, siempre distinto al presidio donde ejercían su oficio. Un hijo de Miguel Gutiérrez, soldado de la compañía volante en 1717, contrajo matrimonio con una mujer originaria de El Gallo, lo cual muestra la relación entre los miembros de los presidios, que aparece de manera clara en los padrones de Mapimí y de El Gallo.

26 AHMP.FC.C10. 002037. "Listas remetidas por los capitanes de las compañías y presidios de esta gobernación”, 1717; AHMP.FC. 601.002.025. “Autos de visita de Gregorio Álvarez Tuñón y Quiroz, visitador general de las armas en Nueva Vizcaya” 1723. Ese documento fue paleografiado por Rita Soto. AHMP.FC. E14.034.139. “Padrón de soldados de la compañía volante de campaña”, 22 de mayo de 1720, documento proporcionado por Roberto Baca. También se cuenta con la lista de los primeros soldados de la compañía volante en San Bartolomé: AHMP.FC.C1 0.001.024: “Libro donde se asientan los soldados de campaña”, 1688. El ensayador Francisco de Escárcega fue comisionado para la muestra se indican con una " $F$ " a los que se encontraban fuera: capitán Antonio de Medina (F), Matías Navarro (por al alférez Joseph Velázquez), Lucas Sánchez de Cuellar y Razanal (F), Isidro Fernández (por Sebastián Fernández (F), Joseph de Villalba (F), Alfonso Muñoz de Rivera (F), Francisco Jiménez (F), Juan López de Mesa (F), Vicente de Amparán, Diego de la Riba (en lugar de Lorenzo de Sandoval, difunto), Nicolás de Vergara (F), Melchor de la Torre, Juan Velázquez, Antonio Méndez de Noroña (por Diego de Galavis), Antonio de Vergara, Manuel de Sapien (F), Andrés de Mendoza (F), Tomás Camacho (en lugar de Salvador Rangel Pesqüero (F), José López, Andrés Fernández (F), Cristóbal Favela (F), Cristóbal de Alfaro, Francisco García, Tomás González (F). Nicolás de la Peña, el sargento Marcos de Ávila y Juan de Bribiesca se encontraban con la caballada. Documento paleografiado por Manuel Rosales. 
Algunos provenían de la Nueva España o de la Nueva Galicia (de poblados cercanos a Zacatecas).

La mayoría de los soldados empadronados tenía alguna cicatriz o discapacidad, al parecer resultados de acciones bélicas, lo cual muestra que sí las emprendían con cierta frecuencia. La tercera parte de ellos se reportaron como "hoyudos de viruela" o "picados de viruela", marcas que adquirieron por haber sido contagiados por esta enfermedad epidémica que reincidía más o menos cada diez años en la Nueva Vizcaya, y fue la primera causa de mortalidad durante siglos. La viruela provocaba inmunidad, y por esta razón en España se incorporaba al ejército solamente a hombres que tenían esas marcas, para prevenir un nuevo brote en las fuerzas armadas. A mediados del siglo XVIII, todavía no había medios preventivos contra esa enfermedad. La variolización (introducción de costras infectadas en una pequeña incisión) se aplicó a finales de la centuria y la vacuna hasta 1804 (Cramaussel 2008). ${ }^{27}$

La edad promedio de los soldados rondaba alrededor de los 30 años, la mayoría ejercía ese oficio en sus años mozos. Se salían de la milicia al envejecer, con excepción de los capitanes que pasaban a ser hacendados y se integraban a la oligarquía local. Cerca de 40 por ciento de los soldados eran mestizos, coyotes o mulatos, es decir, pertenecían a las castas. En 1671, el virrey había ordenado que en las tropas presidiales "todos o los más fueran españoles, permitiendo algunos castizos de buena opinión y proceder prácticos de la tierra" (Porras Muñoz 2006, 351), pero esa regla no se respetó como lo muestra la presencia de numerosos mestizos, coyotes y mulatos tanto en los presidios de la Nueva Vizcaya, como en la compañía volante (véase anexos 2, 3 y 4 ).

A cada soldado, enlistado en los tres padrones de principios del siglo XVIII, se le trató de encontrar en las partidas de bautizo y en las informaciones matrimoniales asentadas en la iglesia de San Pedro

27 Al final del presente artículo aparecen los cuadros de procedencia de los soldados. No se encontraron casos de la compañía volante, por lo que sólo se indica el origen de los de Mapimí y El Gallo (el siguiente presidio en el camino real hacia el sur). El cuadro para San Bartolomé se construyó con base en las partidas de bautizo, porque en los listados no se menciona el origen, ni la calidad de los soldados. 
(ahora parroquia de San Bartolomé, en Valle de Allende, Chihuahua) ${ }^{28}$ (véase anexo 2). Los solteros escapan desde luego con mayor facilidad a la investigación, puesto que pudieron haber nacido en otro lugar; no aparecen en información matrimonial alguna, ni tuvieron descendencia reconocida; sólo se les puede encontrar en las listas de entierros, siempre y cuando hubieran muerto allí. En la mayor parte de las partidas no se especifica la calidad de los soldados pero, en 9 de los 19 casos en que sí se señala, aparecen hombres pertenecientes a las castas y dominan los mulatos; su proporción era comparable por lo tanto a la constatada en los presidios de Mapimí y El Gallo (40 por ciento). ${ }^{29}$

En el Valle de San Bartolomé y en toda la Nueva España (Carbajal 2014) había familias pluriétnicas de soldados, en las que a los hermanos de sangre se les asignaban calidades distintas entre sí. Por ejemplo, el soldado mestizo Marcos Fernández se casó con una mestiza, tuvo un hijo mestizo y otro lobo. Por otra parte, se documentaron dos casos de padres mestizos o mulatos que tuvieron hijos indios, lo cual es muy interesante porque los indios no podían ser legalmente soldados de la compañía, ni de presidios. Sin embargo, en el de San Francisco de Conchos había uno calificado de "indio", en el padrón de 1717.30 Cabe también la posibilidad de que hubiera indios que se hacían pasar por personas de las castas para integrar la compañía volante. Gabriel García Martínez tuvo una hija india, la cual se casó, en 1765, con un indio de padres desconocidos. En 1781, una hija de Pedro José de Soto y Bernarda Chaparro, quien era india y natural de Atotonilco (hoy Villa López, Chihuahua) se casó con José Antonio Pacheco, natural de

La captura de los datos estuvo a cargo de los estudiantes del Colegio de Estudios Científicos y Tecnológicos de Valle de Allende, quienes efectuaron su trabajo social bajo la dirección de Rita Soto. Manuel Rosales pasó la información a una base de datos de Excel, que luego fue proporcionada por Rita Soto.

29 El soldado Manuel Burciaga se casó con una mulata, en 1728, y tuvo tres hijos de la misma calidad en 1734, 1740 y 1741. José Melancio Hernández tuvo dos hijos mulatos, en 1728 y 1730. Manuel Ponce, esposo de María Luisa Gutiérrez, bautizó también a una hija mulata, en 1730. Javier Gómez tuvo una hija mestiza, en 1725, con Mateo Méndez el mismo año. Hubo hijos de soldados que se casaron con mulatas, como la de Santiago de la Rosa, en 1745, o el de Bernardo Cobos, en 1726. Miguel Gutiérrez, esposo de María de Amparán, era el padre de José, quien aparece en 1736, como "sargento de volanta”, y se casó con una mulata de padres desconocidos, en 1736.

30 AHMP.FC.C 10.002.037. “Listas remetidas por los capitanes de las compañías y presidios de esta gobernación”, 1717 . 
Parral. La pareja tuvo otros dos descendientes calificados de mestizos; su hija se casó con un indio de Santa Cruz de Tapacolmes, en 1764, y uno de sus hijos con una mestiza delValle de San Bartolomé, en 1766.

La mayor parte de los soldados era de origen humilde, de hecho muy pocos sabían firmar su nombre, pero ninguno estaba cumpliendo una condena; obtener una placa de soldado les permitía al menos ocupar un lugar en la sociedad y tener asegurado su sustento. Con los datos incluidos en el anexo 2 se pueden comparar los padrones de soldados de la compañía volante de 1717, 1720 y 1723; se repiten los apellidos, lo cual sugiere que había miembros de la misma familia en la tropa. Se corroboró esta hipótesis al analizar las partidas eclesiásticas donde aparecían los soldados mencionados en los padrones. La compañía contaba con parejas de padres e hijos, como Miguel Gutiérrez, padre de José, ambos soldados en 1717. Miguel Cobos era hijo de Bernardo Cobos, y ambos fueron empadronados en 1723. Hubo familias que contaban con varios soldados en su seno, como los Talavera o los Gutiérrez, que ocuparon varias plazas en los seis años estudiados. Hubo también hijas de soldados que se casaron con integrantes de la misma compañía o de otros presidios. La relación con el presidio vecino, de San Francisco de Conchos, parece haber sido particularmente estrecha. Muchos soldados de San Bartolomé fueron sargentos, antes o después, en San Francisco de Conchos, donde su salario era inferior. Oficiales de Conchos pasaron a ser simples soldados en la compañía volante donde cobraban más. ${ }^{31}$

Cotejar los padrones de soldados de la compañía volante de 1717,1720 y 1723 permite darse cuenta que no todos los soldados

31 Entre los enlistados en los padrones encontrados estaba el soldado Marcos Fernández, quien era sargento en Conchos, en 1707, cuando contrajo matrimonio en el Valle de San Bartolomé. José Gutiérrez era sargento de Conchos, en 1715, lo mismo que Francisco Javier Sotelo, en 1716, Cristóbal Talavera, en 1717 (poco antes de ingresar a la compañía volante), Juan del Hierro, en 1718, y Pedro Sapien Salas, en 1719. Felipe Ledesma estuvo como sargento en Conchos, en 1720, y también Juan José de la Cruz Cardoso, en 1721, y Juan Manuel Ponce de León, en 1726. Todos ellos contrajeron matrimonio en la iglesia del Valle de San Bartolomé. José Gabriel García Martínez, presente en 1723, era nativo de Conchos y había sido también sargento en el mismo presidio, en 1721, ostentaba ese grado cuando se unió con Manuela del Hierro. Lucas, probablemente hermano suyo, a los 18 años era soldado en Conchos al casarse con María de Aguilar Caballero, en el Valle de San Bartolomé, en 1721. Manuel Burciaga, exsoldado de la compañía volante, fue ascendido a sargento en San Francisco de Conchos, como hace constar en su partida de casamiento con María de Villanueva, en 1726. 
permanecieron durante seis años seguidos en ella, que contaba con $30 .^{32}$ De los 58 hombres, sólo 9 figuran en las tres listas, es decir, poco menos de la tercera parte de los soldados siguió en la compañía volante en ese lapso. No se sabe si los demás renunciaron, desertaron, fueron trasladados a otro presidio, o pusieron en su lugar a un pariente. Parece difícil que renunciaran porque tenían deudas con el capitán, quien les adelantaba bienes sobre su salario, pero las demás eventualidades, en cambio, están abiertas. Quizá el capitán saliente pasaba las deudas de los soldados a su sucesor, como ocurría en la compraventa de haciendas, donde las de los peones formaban parte de los haberes. Pero esos traspasos no dejaron huellas escritas, como tampoco la contratación de soldados antes de finales del siglo XVIII.

Por otra parte, estaba el caso de un soldado-hacendado, Juan Muñoz de Olvera, quien no tenía necesidad de cobrar un salario, aunque estar en el padrón de la compañía volante tal vez le servía para complementar sus ingresos. Pero es probable que mandara a otra persona para que cumpliera con sus obligaciones de soldado, cuando se trataba de ir a combatir a los indios o "convoyar", según la expresión de la época, a los trajinantes del camino real. Este personaje había contraído alianzas matrimoniales muy convenientes, que le permitieron adquirir dos haciendas. Josefa de Ontiveros, su primera esposa heredó la hacienda de La Gomera (ahora cerca de Hidalgo del Parral, Chihuahua) que recayó en él cuando quedó viudo por primera vez. Gracias a la dote que aportó su segunda esposa, y por compra al resto de sus cuñados herederos de Juan Ponce de León, Muñoz de Olvera pasó a ser propietario de la estancia de San Nicolás del Molino, a una legua río arriba del Valle de San Bartolomé (que dio origen a Talamantes, Chihuahua). ${ }^{33}$

El hecho de haber encontrado a casi todos los soldados en los registros de la parroquia de San Pedro muestra que sus familias

32 AHMP.FC.C 11.017.177. "Diligencias hechas para las providencias que se han de tomar contra los indios enemigos, por el ataque que hicieron a la villa de Santiago de Monclova, en la provincia de Coahuila”, 1721. En esa campaña salen el cabo Manuel Burciaga, Antonio de Ortega, Gabriel García, Cristóbal de Talavera, Jacinto de Talavera y Ventura Ruiz, que figuran en la lista de 1720. Pero se enlista Bartolomé de Ledesma en lugar de Felipe, y aparecen Eduardo Delfín y Francisco Javier Chávez, que no se incluyen en el padrón de 1720. AHMP.FC.E.14.031.122. Testamento de Juan Muñoz de Olvera, 8 de mayo de 1712. Se agradece a Roberto Baca haber señalado y trascrito este documento. 
estaban establecidas en el Valle de San Bartolomé. Éstos contribuyeron al repoblamiento de un lugar fundado en 1574, donde quedaban muy pocos habitantes a finales del siglo XvII, y donde la misión en tanto que asentamiento ya no existía. Todos los indios radicaban en las haciendas salvo unos ocho o diez, quienes, al decir de los vecinos, eran ya de sangre mezclada. Los frailes del convento les dispensaban los sacramentos pero cobraban los aranceles correspondientes a los hacendados (Cramaussel 1998). ${ }^{34} \mathrm{Al}$ ser asignada la compañía volante al Valle de San Bartolomé, de golpe se establecieron 30 personas más en la zona. La mayoría de los 58 soldados empadronados en 1717 , 1720 o 1723 se casaron en el Valle de San Bartolomé, varios con mujeres que pertenecían a familias antiguas de la provincia de Santa Bárbara, y tuvieron vástagos durante muchos años en la región. Esas uniones están consignadas en el anexo 2.

No se cuenta con una lista exhaustiva de todos los capitanes (véase anexo 1), perola información reunida acerca de los que permanecieron más tiempo en el cargo permite elaborar un perfil de esos personajes. Ellos también contrajeron alianzas matrimoniales en la cuenca del río Florido, varios eran originarios de la región, otros eran recién llegados, casados con ricas herederas, y no todos tenían experiencia militar, y algunos más eran parientes de los gobernadores. En los demás casos, fue probablemente gracias al capital previo de ellos o de sus esposas que el gobernador les dio el nombramiento de capitán de la compañía volante, puesto que tenían que tener suficientes recursos para que ésta marchara bien, para adelantar la comida, y para que un comerciante los aviara con los bienes necesarios.

Antonio Medina fue el primer capitán que encabezó la compañía volante de campaña, ya estacionada en el Valle de San Bartolomé. Cuando se trasladó la tropa a ese pueblo, Medina llevaba 19 años como soldado y alférez de ésta. En 1677 ya se le mencionaba entre los soldados de la compañía volante, comandada por Nicolás Rodríguez Rey, quien pasó revista en Parral ante el gobernador Lope de Sierra y Osorio. Fue testigo, ya con el cargo de capitán, en la boda de Tomás González, uno de los soldados de la tropa, y María Mendoza, celebrada

34 AHMP.FC.C11.018.186. “Testimonio de los autos que se fulminaron por la sublevación y pacificación de los indios de nación tacuitatomes, alias chizos...”, 1723. 
en la capilla de San Antonio en la hacienda de Valsequillo, el 2 de febrero de 1689 (Informaciones matrimoniales. Parroquia de San Bartolomé, Valle de Allende, Chihuahua). Después de 1691, Antonio de Medina, de edad avanzada, trató sin éxito de ser nombrado capitán de la nueva compañía volante de la provincia de Sonora (Porras Muñoz 2006, 340-342); pero no dejó más rastro en el archivo parroquial, ni tampoco tuvo puestos de consideración después. Es posible que haya muerto en alguna expedición fuera de la provincia.

Vicente de Amparán, natural de Irún, en Vizcaya, se casó con Josepha Muñoz Polanco en el Valle de San Bartolomé, el 24 de agosto de 1688. La pareja tuvo cinco hijos. ${ }^{35}$ Ese capitán, al que se menciona en el padrón de soldados de 1688, no se encuentra después en las partidas eclesiásticas tal vez porque habitaba en el presidio de San Miguel de Cerro Gordo, donde fungía como interino en $1717 .{ }^{36} \mathrm{La}$ fecha de su matrimonio corresponde con la del establecimiento de la compañía, lo cual podría señalar la velocidad con la que oficiales y soldados, al igual que todos los recién llegados, trataban de contraer alianza con alguna mujer de la región. Aparece Vicente de Amparán como capitán reformado, desde 1717, y falleció antes de 1737. Una de sus hijas se casó, en 1727, con Vicente Ponce de León, un soldado de Conchos.

Están asentados también en los documentos de la Iglesia los nombres de los vástagos del capitán Antonio de Rodela, originario del Valle de San Bartolomé. En 1705 ya era alférez cuando Joseph Fernández de Córdoba, sin duda pariente del gobernador del mismo apellido, comandaba la compañía volante. ${ }^{37}$ Fue protector de los indios (tarahumaras, tobosos y chizos) en San Francisco de Conchos en 1712, y comandante de la compañía volante antes de ser nombrado capitán de las fronteras de San Buenaventura de Atotonilco y teniente de alcalde mayor, en 1721, por el gobernador Martín de Alday. ${ }^{38}$

35 Archivo Parroquial de Valle de Allende, caja 254, folder 1, Padrón de comulgantes de 1737 , paleografiado por Manuel Rosales.

36 AHMP.FC.C 10.002037. "Listas remetidas por los capitanes de las compañías y presidios de esta gobernación”, 1717 .

37 AHMP.FC.C 11.13.138. “Autos contra los acoclames..., 1705.

38 AHMP.FC.D 33.23.180. Juicio de residencia de Martín de Alday, 1721. AHMP.FC.E14.031.122. Copia proporcionada por Roberto Baca, quien la obtuvo de Manuel Rosales. 
Rodela era mayordomo de la hacienda de Santa María de Atotonilco y hablaba acoclame, el idioma de los indios de la región que habitaban la sierra vecina del Diablo, que fueron reducidos en 1715 en la misión de San Buenaventura de Atotonilco, antes de huir poco después con la caballada de la hacienda. El capitán Rodela adquirió, en 1732, de José Ascue y Armendariz, la hacienda de Santa Ana de Tierra Blanca de los Ahorcados, en la margen izquierda del río Florido, la cual se encontraba despoblada. Esta propiedad constaba de quince y medio sitios de ganado mayor (Almada s/f) y por composición después se amplió con nueve sitios más. Rodela se había casado con Ana Peinado, quien pertenecía a una antigua familia de la provincia de Santa Bárbara, a juzgar por su apellido. La pareja bautizó en el templo a Tomás, el 18 de marzo de 1723; a María Gertrudis, el 15 de abril de 1725; a María Antonia el 16 de febrero de 1727 y en años posteriores a Juan de Dios y a Tadeo. Tierra Blanca fue vendida en 1749 por los herederos de Antonio de Rodela, en 5 mil pesos, al capitán de San Francisco de Conchos, José de Berroterán, quien tuvo que traspasarla porque estaba cargada de capellanías. La propiedad fue a dar finalmente a manos de don Antonio Saenz Moreno, el dueño de la hacienda de Dolores, que colindaba con la de Santa María de Atotonilco (Almada s/f).

El cargo de capitán a veces era asignado a personas que se casaban o bautizaban a sus hijos en Parral, como Juan de Salaices, conocido hacendado de la región, quien quizá nunca residió en San Bartolomé; tal vez fue hijo de Antonio de Salaices, natural de Las Alcarrias, en la provincia de Guadalajara, en España, quien había llegado en 1640 al pujante real de Parral con su hermano Juan, mercader y minero. Murió, en calidad de soltero, en 1676. El capitán de la compañía volante entre 1717 y 1720 ya había ocupado ese cargo en ella antes de trasladarse a San Bartolomé; en 1687, el gobernador José de Neira y Quiroga lo propuso en segundo lugar en la terna para que fuera capitán vitalicio de El Pasaje, pero el virrey escogió al primero llamado Escorza (Almada s/f). Juan de Salaices estaba emparentado con los Hierro y Cereceda, principales hacendados de la provincia de Santa Bárbara (Cramaussel 2006, 411).

También es muy ilustrativa la carrera de Joseph Gabriel Sánchez de Sarmiento, quien llevó a cabo la campaña punitiva contra los tobosos en 1721. Llegó a la provincia de Santa Bárbara en 1718, 
aparentemente después de obtener el título de "capitán a guerra y justicia del Valle de San Bartolomé”, es decir, que ejercía la justicia a nombre del alcalde mayor en su ausencia. Fue visitador de Indé y Guanaceví por orden del gobernador, y redujo a indios sublevados en Santa Cruz de Nazas (hoy ubicado en el norte del estado de Durango). Dos años después obtuvo el cargo de alcalde mayor de San Bartolomé, lo renovaron en el puesto en 1721, y en 1722 por un año más. En 1721, el gobernador Martín de Alday lo nombró “capitán de caballos de corazas de la compañía volante de arcabuceros que tiene por pie de ejército este reino de la Nueva Vizcaya," al renunciar el capitán Gaspar de Cosío. A su salario de 200 pesos de alcalde mayor se sumaron, a partir de entonces, los 600 pesos anuales de capitán de la compañía. Al parecer no tenía bienes además de su salario, y al no casarse con una mujer perteneciente a la oligarquía local, como lo había hecho su antecesor, Antonio de Rodela, cometió el error de no asegurar su carrera política y a su descendencia. Pero se hizo compadre de un rico hacendado de la provincia, el capitán Diego Moreno, quien llevó a cabo su primer juicio de residencia a pesar del parentesco espiritual que lo vinculaba con el alcalde mayor, Martín de Alday. El hecho fue denunciado después por sus enemigos, entre los cuales el principal era Felipe Ponce, quien codiciaba también el cargo de capitán de la compañía, ${ }^{39}$ y era tal vez pariente de Manuel y Nicolás, dos soldados que aparecen en los padrones.

Es probable que Joseph de Idoyaga, natural de Lequeitio en Vizcaya, sucediera a Joseph Sarmiento. En 1731 era ya "capitán vitalicio de la compañía volante“, el primero en ostentar este título y fue nombrado al mismo tiempo alcalde mayor de San Bartolomé, al igual que su antecesor. ${ }^{40}$ El 18 de mayo de 1732, Idoyaga se casó en Parral con Ana Rita de Orrantia, hija del próspero comerciante Cristóbal de Orrantia y doña Teresa de Montenegro y San Jurjo, ${ }^{41}$ tuvo cinco hijos que recibieron el bautizo en el templo de San Pedro. Joseph de Idoyaga está mencionado en el padrón de comulgantes de 1717

39 AHMP.FC.D33.23.180. Juicio de residencia de Martín de Alday, 1721.

40 AHMP.C.09.001.005. "Testimonio sobre el nombramiento que el gobernador Barrutia teniente de capitán del presidio de Conchos...”, 1731.

41 Ortelli $(2007,38)$ menciona que era pariente de los Jugo y Urquidi, prominentes familias de la región. Este parentesco se debe al citado matrimonio de Joseph de Idoyaga. 
de San Bartolomé, ${ }^{42}$ y era todavía capitán de la compañía volante en 1750; la muerte lo sorprendió antes de 1752. Ejerció el cargo durante más de dos décadas, y aunque era de origen vasco, casó a sus cuatro hijas con peninsulares que no lo eran, se menciona el lugar de nacimiento de tres de ellos: Oviedo, Madrid y Villoslada en La Rioja. Lo más importante era que sus yernos fueran originarios de los reinos de Castilla. El capitán seguía un patrón común a toda la oligarquía local: las hijas se unían en matrimonio a recién llegados de buena alcurnia, los hijos con herederas locales, cuando no iban a probar suerte en regiones por colonizar, o se dedicaban al sacerdocio.

Los integrantes de la compañía de campaña tuvieron que dejar sus hogares del Valle de San Bartolomé a mediados del siglo XVIII, por orden real, y pasar a convivir en un verdadero recinto presidial. Fue al parecer Juan de Dios Rodela, el hijo del personaje del mismo apellido que había sido capitán de la campaña volante, quien junto con Saenz Moreno, el hacendado vecino, solicitó la fundación de un presidio cerca de su hacienda de Tierra Blanca (al norte de la actual Ciudad Jiménez, Chihuahua), que amenazaban los indios de guerra (Almada s/f, 9-10). La solicitud recibió una respuesta positiva del virrey y la compañía volante fue trasladada a Huejuquilla, donde se erigió un verdadero presidio en 1752, en el lugar de la actual Ciudad Jiménez, Chihuahua. Pedro de Rivera ya había preconizado, en 1726, desplazar también la compañía volante hacia el este de San Bartolomé, a Atotonilco (hoy Villa López, Chihuahua), a unos kilómetros al sur de Huejuquilla, probablemente para proteger de los indios de guerra el flanco oriental de la provincia de Santa Bárbara (Porras Muñoz 2004, 56-57).

A partir de entonces, el presidio de Huejuquilla, fundado el 4 de enero de 1753, sirvió más de baluarte del imperio español contra los indios rebeldes, que para la protección de los viajeros que transitaban entre Cerro Gordo, el Valle de San Bartolomé, Santa Cruz de Neira y Chihuahua. El capitán Bernardo Antonio de Bustamante y Tagle, quien llevaba un estandarte con la virgen de Santa María de las Caldas que dio origen al patronazgo espiritual del presidio de Huejuquilla, 
sucedió a Idoyaga al mando de la compañía, cuyos efectivos habían aumentado mucho en 60 años. Al principio la tropa se componía de 20 hombres, en 1752 fueron 66 los trasferidos al nuevo presidio; el año anterior se habían suprimido los de El Pasaje, Cerro Gordo, El Gallo y San Francisco de Conchos (Porras Muñoz 2004, 51-58).

El objetivo era repoblar las haciendas de Huejuquilla, Tierra Blanca, Ojo de Barraza (ubicación desconocida) y Cañas (quizá Sextín de Cañas, al sureste de San Bartolomé), las cuales estaban "yermas y despobladas" desde la rebelión de 1722. El capitán Bernardo Antonio de Bustamante y Tagle nació en Madrid, en 1708, de una pareja que provenía de la provincia de Laredo; su padre era abogado de los Consejos del Rey y consultor del Santo Oficio. Bustamante optó por la carrera militar en las Indias Occidentales y a partir de 1726 se desempeñó como soldado, luego alférez y teniente de capitán en el presidio de Santa Fe, en Nuevo México, donde se casó. Fue fundador del pueblo de Sandía, al norte de la actual ciudad de Alburquerque. En 1750, el gobernador de la Nueva Vizcaya lo nombró capitán vitalicio del presidio de Cerro Gordo y dos años después cumuló este cargo con el de capitán de Huejuquilla, donde murió en 1773. Lo había alcanzado tres años antes su hermano José Antonio, quien contrajo matrimonio con doña Josefa Rodela, tal vez familiar de Antonio de Rodela (Carrillo y Cramaussel 2015).

Adquirir el cargo de capitán de compañía de campaña o de algún presidio garantizaba el ascenso social y la pertenencia a la oligarquía local, y a veces incluso la obtención de posiciones más altas de la jerarquía política, que en esa época se compraban al mejor postor. La carrera de Martín de Alday, quien falleció en la década de 1720, es el mejor ejemplo de esto; antes de ser nombrado gobernador de la Nueva Vizcaya ya había ejercido el cargo de capitán vitalicio en el presidio en Nuestra Señora de la Limpia Concepción del Pasaje (Almada s/f, 23). Como sucedió en el caso de todos los oligarcas de la provincia en los siglos anteriores (Cramaussel 2006, 272-295), el origen del poder de los capitanes era de tipo militar. Los que llegaban a los cargos más altos de la sociedad y se mantenían en su cúspide estaban en la frontera con los indios rebeldes. Tenían tratos tan estrechos con ellos, que eran capaces de imponer la paz o la guerra en la región. 


\section{Conclusión}

La compañía volante de campaña del Valle de San Bartolomé y las presidiales no diferían en sus funciones, ni en su composición social. Los soldados de la compañía volante recorrían el camino real y se unían a la fuerza armada de los demás presidios, cada vez que lo requería el gobernador. Sus miembros percibían un salario, aunque no lo recibían de manera puntual, pero los gastos que causaban las expediciones contra los indios de guerra recaían en buena parte en el vecindario.

Los soldados de la compañía volante dependían de los capitanes para sobrevivir, eran de extracción humilde, y muchos de ellos pertenecían a las castas, y con frecuencia pasaban de un presidio a otro. Los capitanes, en cambio, formaban parte de la oligarquía local, unos por abolengo, otros por haberse casado con herederas ricas o por ser parientes del gobernador en turno. Todos los que permanecieron en la región al final de su vida dispusieron de haciendas y bienes de campo, adquiridos al explotar a los soldados de compañía, y gracias al control que ejercían sobre los indios en tierras que estaban al margen de la colonización española.

Los capitanes no dependían de su oficio como militares para su sustento y su cargo les garantizaba el ascenso social. El estudio prosopográfico muestra los orígenes sociales de los soldados y los capitanes, y cómo sus carreras personales tomaban vías muy diferentes. Pero tanto capitanes como soldados de la compañía volante se avecindaron en la región y su descendencia contribuyó a afianzar el poblamiento de la provincia de Santa Bárbara.

Recibido en febrero de 2015 Aceptado en mayo de 2015

\section{Bibliografía}

Almada, Francisco, R. 1968. Diccionario de historia, geografía y biografía chihuahuense. Chihuahua: Universidad de Chihuahua. 
Almada, Francisco, R. s/f. Resumen geográfico del municipio de Jiménez. Ciudad Juárez: El Labrador.

Álvarez, Salvador. 1999. La hacienda presidio en el camino real de tierra adentro. Transición 22: 48-71.

Borrero Silva, María del Valle y Jesús Dénica Velarde Cadena. 2013. Las compañías de ópatas de la provincia de Sonora. En Indios, españoles y mestizos en zonas de frontera, siglo XVII-XX, coordinado por José Marcos Medina Bustos y Esther Padilla Calderón, 95-117. Hermosillo: El Colegio de Sonora, COLMICH.

Campos Reyes, Clementina. 2012. Aspectos demográficos de Namiquipa, en el norte de la Nueva Vizcaya (1802-1815). Revista de Historia 4: 115-132.

Carbajal, David (coordinador). 2014. Familias pluriétnicas y mestizaje. Guadalajara: Universidad de Guadalajara.

Carrillo Valdez, Celso y Chantal Cramaussel. 2015. Don Bernardo Antonio de Bustamante y Tagle (1708-1773), reformador de los presidios y fundador de Nuestra Señora de las Caldas de Huejuquilla. Revista de Historia 7: 11-42.

Cramaussel, Chantal. 2014. El exterminio de los chizos, sisimbles, acoclames y cocoyomes del bolsón de Mapimí. Revista de Historia 6: 35-56.

Cramaussel, Chantal. 2008. La lucha contra la viruela en Chihuahua durante el siglo XIX. Relaciones 114: 101-132.

Cramaussel, Chantal. 2006. Poblar la frontera. La provincia de Santa Bárbara durante los siglos XVI y XVII. Zamora: COLMICH.

Cramaussel, Chantal. 1998. Sistema de riego y espacio habitado. La lenta y azarosa génesis de un pueblo rural. En Historia y arte en un pueblo rural: San Bartolomé, hoy Valle de Allende, Chihuahua, coordinado por 
Clara Bargellini, 17-91. México: Universidad Nacional Autónoma de México (UNAM).

Cramaussel, Chantal y Salvador Álvarez. 1997. Introducción. En Misiones y presidios de Chihuahua, coordinado por Clara Bargellini, 9-17. Chihuahua: Gobierno del Estado de Chihuahua, Cementos de Chihuahua.

De Rivera, Pedro. 1736. Diario y derrotero de lo caminado, visto y observado en el discurso de la visita general de presidios, situados en las provincias internas de Nueva España. Guatemala, Sebastián de Arévalo.

Gerhard, Peter. 1996. La frontera norte de la Nueva España. México: UNAM.

Griffen, William B. 1979. Indian assimilation in the Francisco area of NuevaVizcaya. Tucson: The University of Arizona Press.

Ortelli, Sara. 2007. Trama de una guerra conveniente. NuevaVizcaya y la sombra de los apaches (1748-790). México: El Colegio de México.

Porras Muñoz, Guillermo. 2006. La frontera con los indios de Nueva Vizcaya en el siglo XVII. Chihuahua: Secretaría de Educación y Cultura del Gobierno del Estado de Chihuahua.

Porras Muñoz, Guillermo. 2001. Iglesia y Estado en Nueva Vizcaya (15621821). Durango: LXI Legislatura del H. Congreso del Estado de Durango.

Porras Muñoz, Guillermo y Guillermo Porras Muñoz (editores y autores de la introducción y notas). 2004. Diario y derrotero de lo caminado, visto y observado en el discurso de la visita general de presidios, situados en las provincias internas de Nueva España. Chihuahua: Gobierno del Estado de Chihuahua. 


\section{Anexo 1}

Lista de los capitanes de la compañía volante de campaña ${ }^{43}$

Antonio Medina, 1688-¿1691?

Simón Rojo Coronel, 1704

Joseph Fernández de Córdoba, 1705

Diego de Molinar, 1707

José Sánchez Sarmiento, 1715

Antonio Rodela, ¿1716?

Juan de Salaices, 1717-1720

Vicente de Amparán, 1720

Gaspar de Cosío, 1721

José Sánchez Sarmiento, 1722

Joseph de Idoyaga, 1731-1752

Bernardo Antonio Bustamante y Tagle, 1752

La lista está incompleta. Almada (s/f, 16) cita también a Beasoain, quien fue capitán en el presidio de Conchos, sin mencionar referencias de archivo. No se conserva información acerca de las acciones de la compañía volante, ni hay padrones de ella en el archivo de Parral después de 1728. Quizá ese tipo de documentación se generó ya en Chihuahua, donde pasó a residir el gobernador de la Nueva Vizcaya, y se perdió en el incendio del archivo a principios del siglo xx, como sucedió con muchos de los papeles relativos a la comandancia posterior de las provincias internas. 


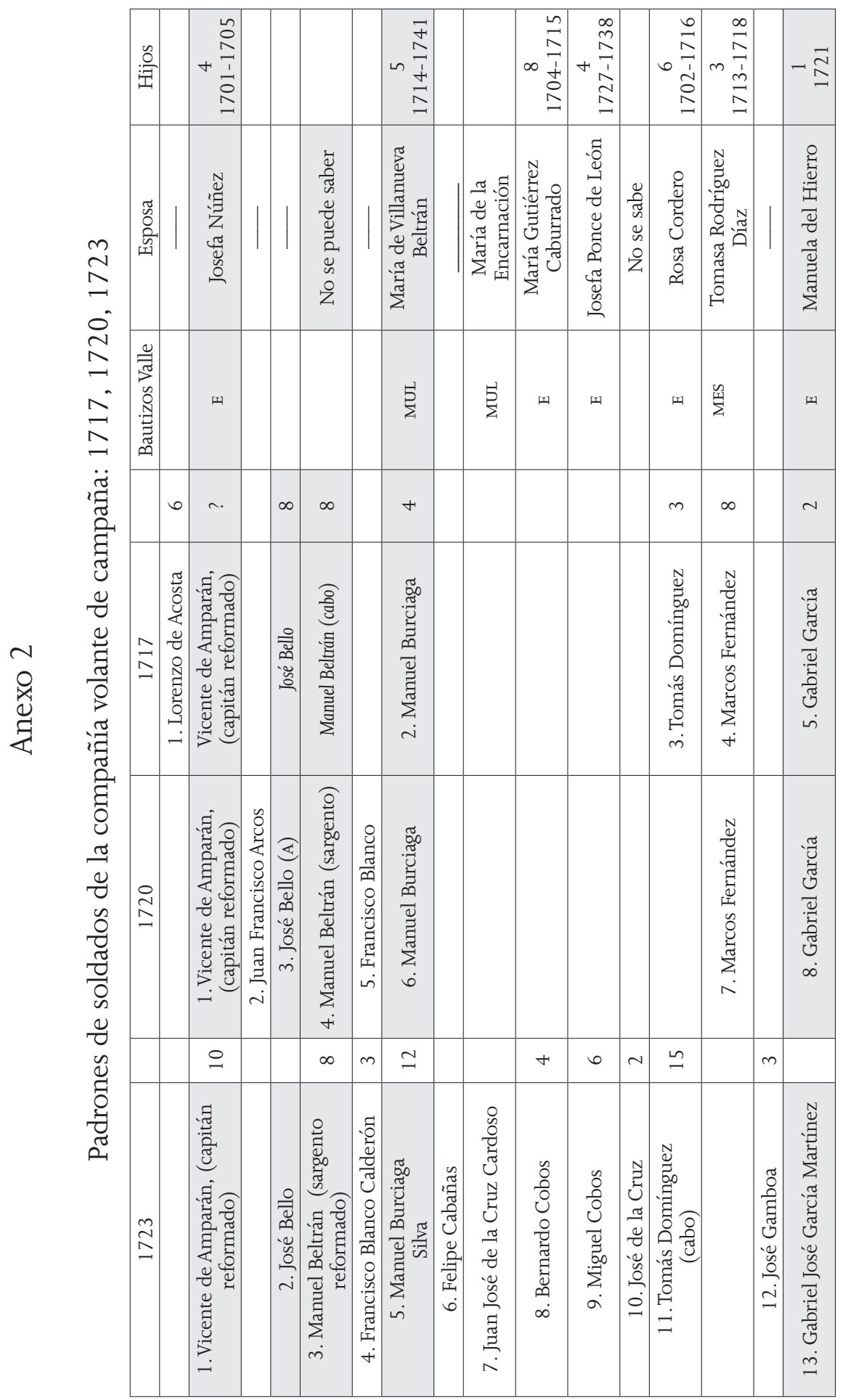




\begin{tabular}{|c|c|c|c|c|c|c|c|c|c|c|c|c|c|c|c|c|c|}
\hline$-\stackrel{n}{\mathbb{N}}$ & & & 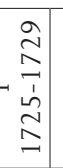 & $-\stackrel{a}{\equiv}$ & 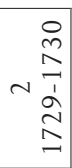 & & & & & & & & 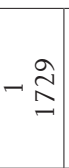 & & 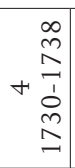 & & $-\stackrel{\stackrel{ \pm}{N}}{=}$ \\
\hline 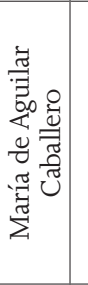 & 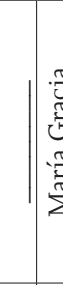 & | & 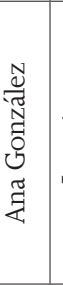 & 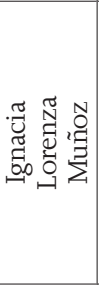 & 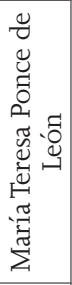 & 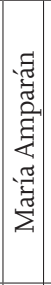 & 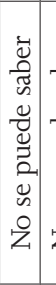 & 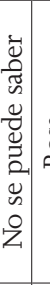 & 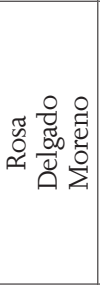 & 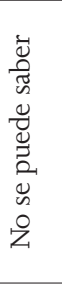 & & 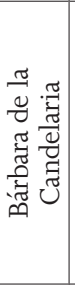 & 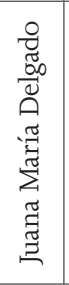 & 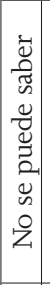 & 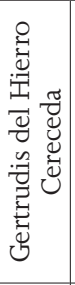 & & 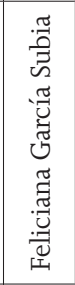 \\
\hline w & & $\vec{s}_{2}$ & $\begin{array}{l}\sum_{2} \\
\sum_{2} \\
\text { na } \\
\text { 至 }\end{array}$ & 피 & 피 & ш & & & & & & 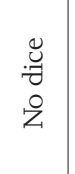 & w & & 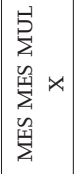 & & 山 \\
\hline & $m+$ & + & t & & in & 6 & & $m$ & 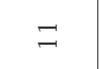 & & $a$ & & & & & $\infty$ & \\
\hline & 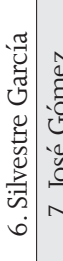 & 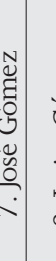 & 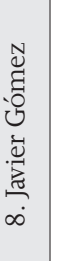 & & 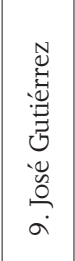 & 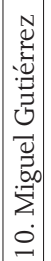 & & 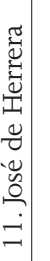 & 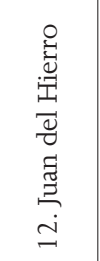 & & 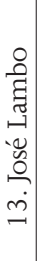 & & & & & 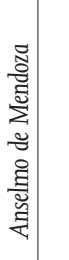 & \\
\hline 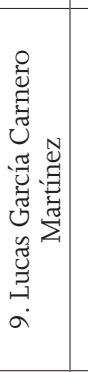 & $\begin{array}{l}0 \\
0 \\
0 \\
0 \\
0 \\
0 \\
0 \\
0 \\
0\end{array}$ & 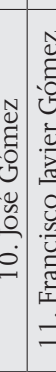 & 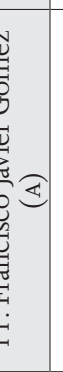 & 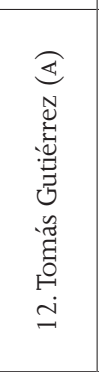 & & & 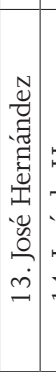 & 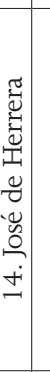 & 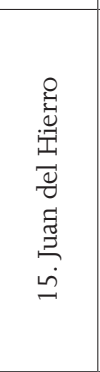 & & & 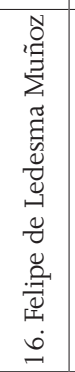 & & & 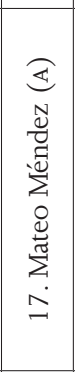 & 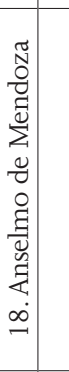 & \\
\hline & & & $m$ & & & & & & & & & & $m$ & in & & & \\
\hline & 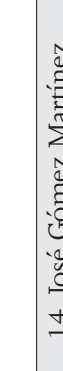 & . & 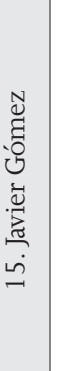 & & & & & & & 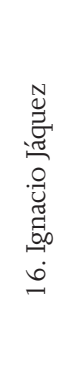 & & & 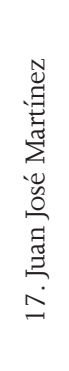 & 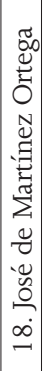 & 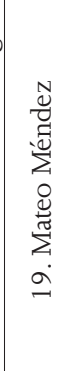 & 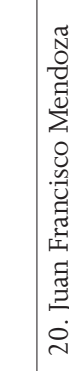 & 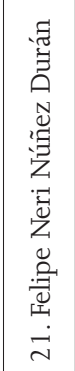 \\
\hline
\end{tabular}




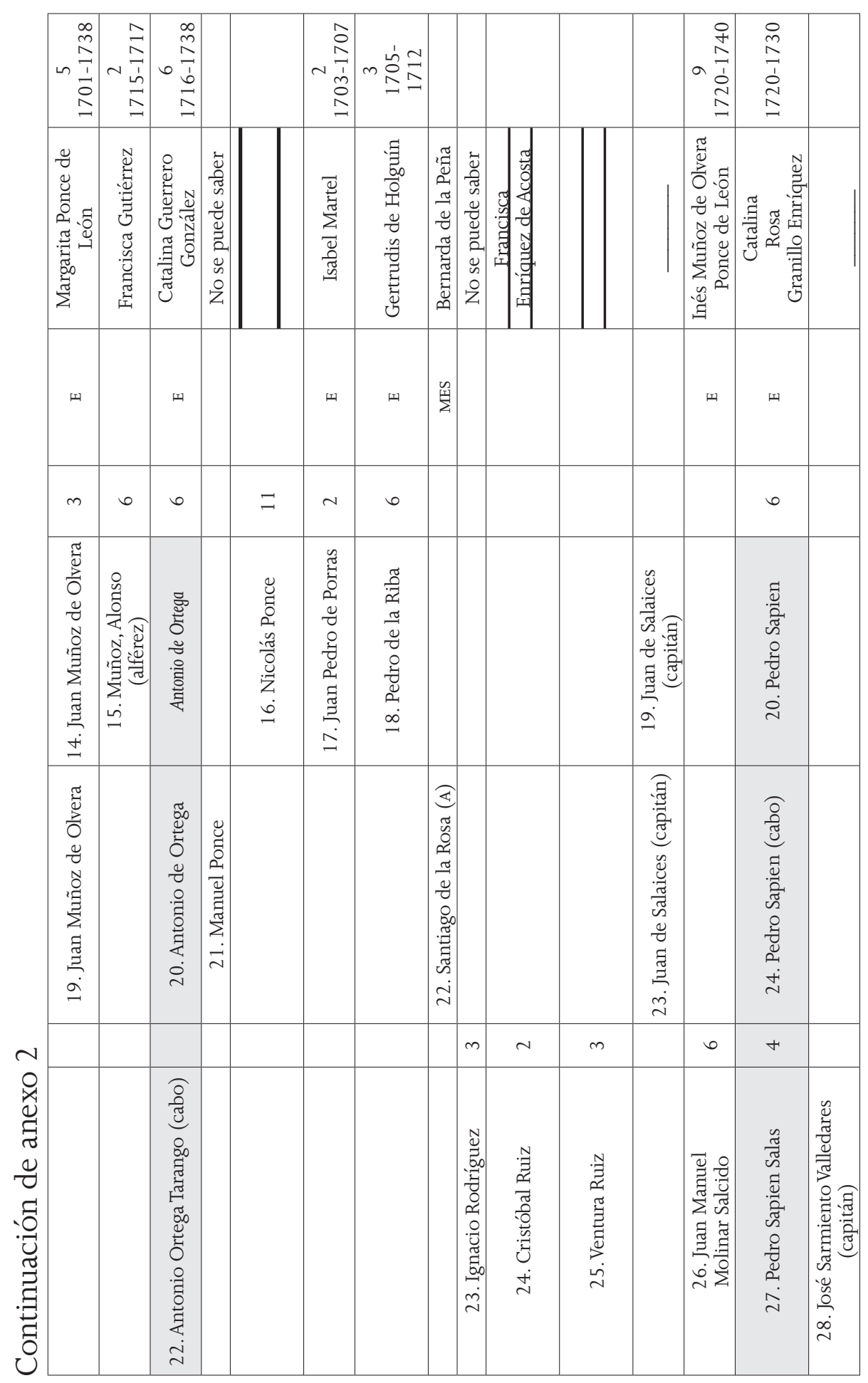




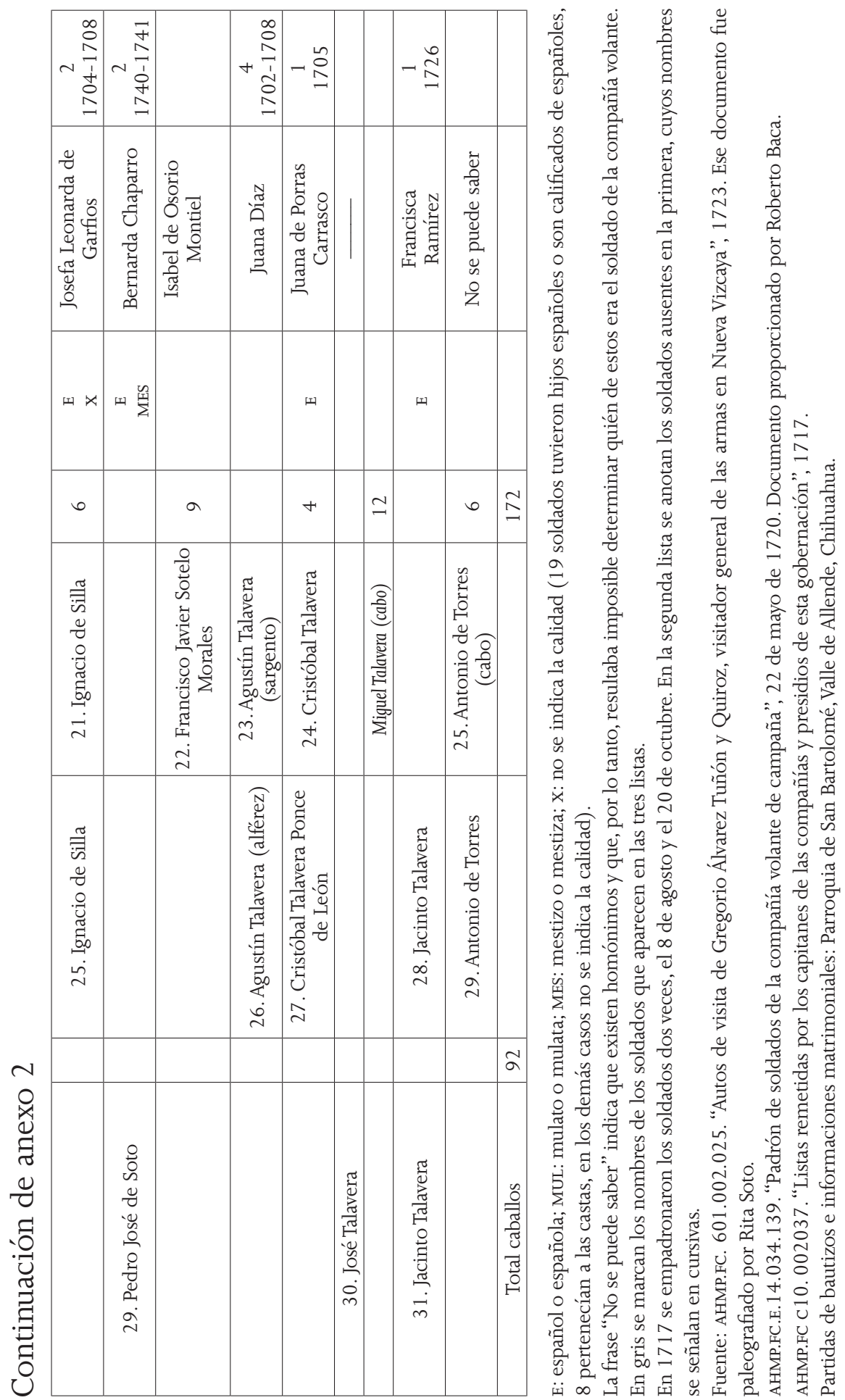




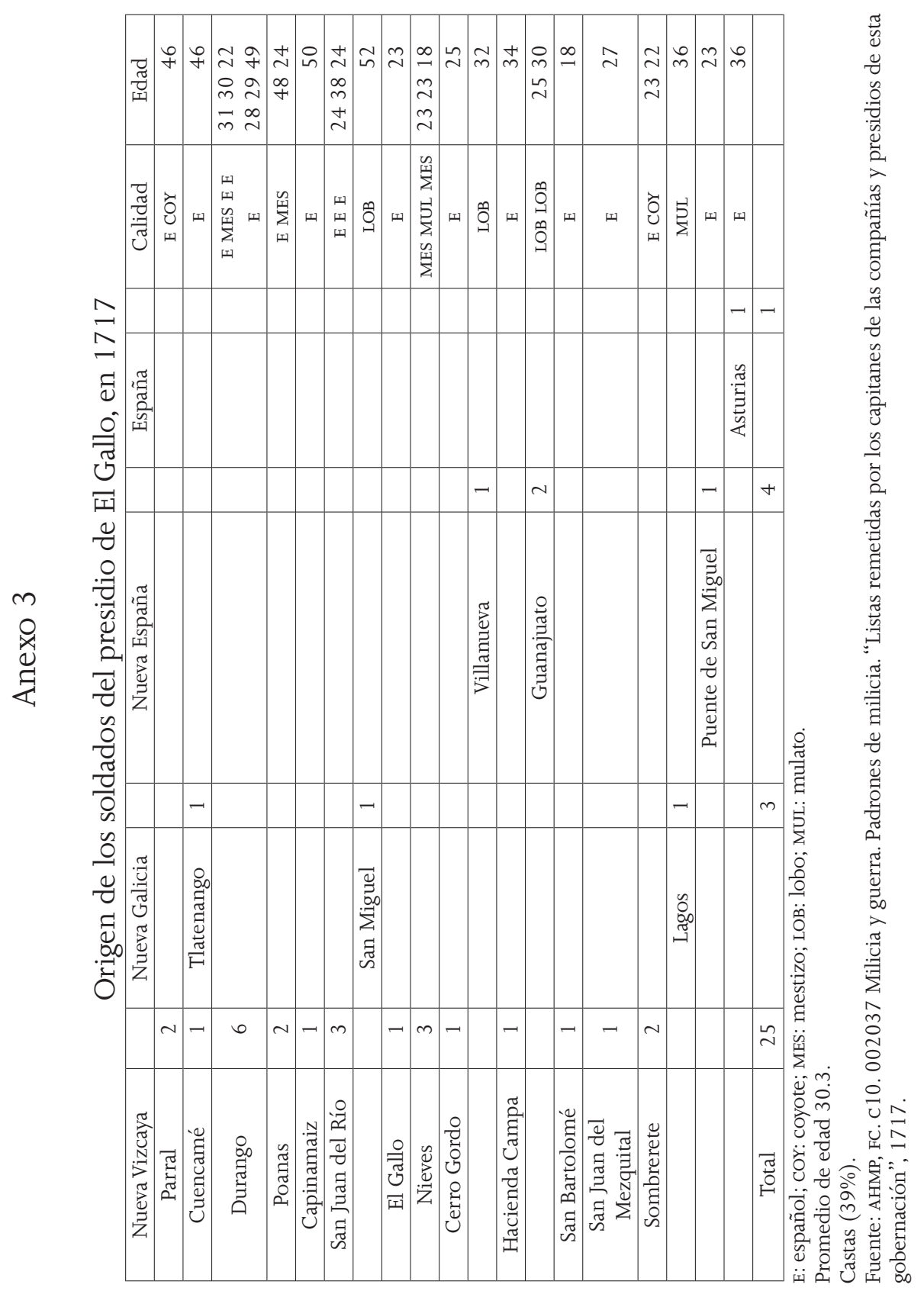




\section{Anexo 4}

Origen de los soldados de Mapimí, en 1717

\begin{tabular}{|c|c|c|c|c|c|c|c|c|c|}
\hline Nueva Vizcaya & & Nueva Galicia & & Nueva España & & España & & Calidad & Edad \\
\hline & & & & & & Guipúzcoa & 1 & $\mathrm{E}$ & 25 \\
\hline Parral & 1 & & & & & & & $\mathrm{E}$ & 24 \\
\hline \multirow[t]{3}{*}{ San Bartolomé } & 2 & & & & & & & E E & 2735 \\
\hline & & Fresnillo & 1 & & & & & E & 36 \\
\hline & & & & & & & & MUL & 26 \\
\hline Súchil & 1 & & & & & & & MES & 23 \\
\hline Durango & 3 & & & & & & & E E E & 353022 \\
\hline \multirow[t]{2}{*}{$\begin{array}{c}\text { San Juan del } \\
\text { Mezquital }\end{array}$} & 3 & & & & & & & $\begin{array}{c}\text { MES MES } \\
\text { COY }\end{array}$ & 282520 \\
\hline & & & & & & Guipúzcoa & 1 & $\mathrm{E}$ & 25 \\
\hline Cerro Gordo & 2 & & & & & & & E MES & 2240 \\
\hline El Pasaje & 1 & & & & & & & E & 32 \\
\hline Conchos & 1 & & & & & & & I & 45 \\
\hline $\begin{array}{l}\text { Santiago } \\
\text { de Basois }\end{array}$ & 1 & & & & & & & $\mathrm{E}$ & 30 \\
\hline $\begin{array}{c}\text { San Juan } \\
\text { del Río }\end{array}$ & 1 & & & & & & & $\mathrm{E}$ & \\
\hline \multirow[t]{3}{*}{ Indé } & 1 & & & & & & & E & 32 \\
\hline & & & & & & & & E & 18 \\
\hline & & & & Guacalcingo & 1 & & & E & 21 \\
\hline \multirow[t]{2}{*}{ Santa Catalina } & 1 & & & & & & & E & 30 \\
\hline & & Teocaltiche & 1 & & & & & $\mathrm{E}$ & 23 \\
\hline Cuencamé & 1 & & & & & & & MES & 23 \\
\hline \multirow[t]{2}{*}{ Nieves } & 1 & & & & & & & E & 26 \\
\hline & & & & $\begin{array}{l}\text { Asientos } \\
\text { de Ibarra }\end{array}$ & 1 & & & $\mathrm{COY}$ & 24 \\
\hline Total & 20 & & 2 & & 2 & & 2 & & \\
\hline
\end{tabular}

E: español; COY: coyote; MES: mestizo; MUL: mulato.

Promedio de edad 27.6

42.8\% de los soldados pertenecía a las castas y había también un indio, los demás eran españoles. Fuente: AHMP, FC. C10.002037. “Listas remetidas por los capitanes de las compañías y presidios de esta gobernación”, 1717. 
